\title{
Exergy Recovery During LNG Gasification Using Ambient Air as Heat Source
}

\author{
Z. Hadid*, A. Zoughaib* \\ Mines Paristech, PSL Research University, Center for Energy efficiency of Systems (CES) \\ assaad.zoughaib@mines-paristech.fr
}

Received 23 October 2016, Accepted 03 January 2017

\begin{abstract}
The market of liquefied natural gas (LNG) is growing and presents the advantage of diversifying supplies. The LNG is fed at a temperature of $-162^{\circ} \mathrm{C}$ and at atmospheric pressure. This study aims at the recovery of the LNG exergy during its gasification and heating before being delivered trough the network. An energy and exergy based analysis is performed for the definition of engine-cycle architectures using the ambient air as a heat source through an intermediate fluid, and LNG as a cold sink. The use of ambient air led to manage frosting problem. The intermediate two phase fluid with a controlled evaporating pressure, recovering heat from the air, is used to avoid the direct contact of humid air with very cold heat exchanger surface in order to limit the frost formation. In this paper, the challenge is to find the best engine-cycle architectures with minimized overall exergy destruction, moving up the efficiency of the entire system. Different systems including Organic Rankine cycles (ORCs) and Brayton cycles, operating as simple or cascade cycles are investigated. Pure working fluid, as well as mixtures of hydrocarbons are considered.
\end{abstract}

Keywords: Exergy analysis, liquefied natural gas, Rankine cycles, Brayton cycles.

\section{Introduction}

Natural gas is converted to liquid form for ease of transport and storage. During liquefaction, a large amount of mechanical energy is consumed. LNG is produced at atmospheric pressure and at a temperature of $-162{ }^{\circ} \mathrm{C}$. however, for normal use, Liquefied natural gas (LNG) should return back to gas state.

For the gasification of LNG, available heat sources on LNG terminal are:

- ambient air

- combustion heat (natural gas)

- seawater

- waste heat

Main gasification processes use seawater or combustion heat as heat source; these processes are energy consumers and presenting a negative environmental impact while LNG accounts for a significant cold source. In the current state of technology, most used gasification systems are:

- Open rack vaporizers - ORV

- Submerged combustion vaporizers - SCV

Other technologies are also being studied, such as the Ambient Air Vaporizer (AAV) which has been the subject of experiments on a small scale, but the drawbacks are ambient temperature dependency and ice formation. Needed heat for the defrosting cycle has to be provided.

In some cases, the integration of the LNG terminal with local cooling energy users is investigated. However, the direct use of cooling energy in the refrigeration industry (eg. air separation, freezing food, etc.) is limited because demand for cooling capacity near the gasification sites is very low. Thus, at this scale, the recovery of the exergy of LNG as electric energy seems to be a preferred option.

In scientific literature, most proposed processes generally avoid using ambient air as a heat source because of ice formation on the heat exchangers; so often they consider the integration of the gasification system with the exhaust gas of a gas turbine (Power plant) used as a heat source for engine cycles or for heating the natural gas. There is also the possibility of using part of the energy of the combustion chamber of the gas turbine as a heat source for the engine cycle. The cycles cited before combined to a power plant unit covers most of the processes proposed by literature. They allow to generate mechanical energy by recovering exergy of LNG and thermal energy from exhaust gases or other available heat source.

Bai and Zhang [1] compared two processes: the first is a combination of nitrogen Brayton cycle, natural gas direct expansion and ammonia-water Rankine cycle (with regenerator), the second is the combination of propane Rankine cycle (with regenerator), natural gas direct expansion and ammonia-water Rankine cycle (with regenerator).

Dispenza et al [2] proposed a helium Rankine cycle using exhaust gas from a gas turbine as heat source. Angelino and Invernicci [3] investigated some working fluids for a Brayton cycle working between LNG as heat sink and gas turbine exhaust at $543^{\circ} \mathrm{C}$ as heat source. Nitrogen seems to be the optimum working fluid for the topping cycle with an efficiency of $63 \%$.

Lu and Wang [4] proposed a cascading power cycle consisting of a direct expansion of natural gas (open cycle) for the recovery of the pressure exergy of LNG and a Rankine cycle of ammonia-water. The ammonia-water Rankine cycle uses LNG as heat sink and a part of heat is generated by the combustion chamber of a gas turbine as a heat source. The exhaust gases of the gas turbine are used to heat up the natural gas to the network temperature.

Qiang et al. [5] designed a combined power cycle, which is composed of propane Rankine cycle recovering exergy of LNG and a direct expansion of natural gas for pressure exergy recovery. LNG is vaporized using the 
propane Rankine cycle and low-grade heat source, it is reheated after expansion in a turbine using the same lowgrade heat source.

Shi and Che [6] used a conventional water vapor Rankine cycle, the generation of steam is carried out by the exhaust gas of a gas turbine. LNG is gasified at the condenser by condensing Rankine cycle steam and hot water extracted from the steam generator. Hot water is also used to heat a portion of the LNG vaporized at $120^{\circ} \mathrm{C}$, used as fuel for the power plant. This proposed system is a cogeneration which recovers the thermal energy of exhaust gas of a power plant, there is no recovery of the LNG exergy because the water condensation takes place at a high temperature $\left(100{ }^{\circ} \mathrm{C}\right)$.

This paper proposes a design of an autonomous LNG exergy recovery system using ambient air as a heat source. The methodology used for the design is a systemic analysis combining both pinch methodology and exergy analysis.

\section{Cryogenic Exergy of LNG (resource characterization)- Energy and Exergy Analysis of the Cold Resource}

Liquefaction of natural gas reduces its volume by more than 600 times, which is convenient for storage or transport at atmospheric pressure. Liquefied natural gas (LNG) is a mixture of several components, the main components are methane, ethane and propane; the mole fraction of these elements is ranging from 98.5 to $99.8 \%$. Given the diversity of the composition of natural gas fields, LNG can be considered on average as a mixture of methane, ethane and propane (85/10/5 mole percent). In this article, the LNG is considered to be pure methane. In gas networks, transport occurs at high pressure (70-100 bar) and distribution upstream of cities is at a medium pressure (10-30 bar). The ratio between the compression energy of natural gas in the vapor state and the pump power of LNG is greater than 20 (Dispensa et al., 2009), therefore, in order to match the required transport pressure, the gasification pressure must be greater than or equal to this required pressure. LNG is usually pressurized in two stages. A first step is operated by the booster pumps submerged in the tanks of LNG; these pumps supply the high pressure pumps which compress the LNG to the final pressure. A gasification pressure of 90 bar is chosen for this study. The calculations are performed assuming a typical flow rate of an LNG gasification module of $160 \mathrm{t} / \mathrm{h}(44.4 \mathrm{~kg} / \mathrm{s})$. Table 1 gives the thermodynamic state of LNG after pressurization and after gasification.

Table 1. Cold sink characterization.

\begin{tabular}{lccc}
\hline & $\begin{array}{c}\text { Transported } \\
\text { LNG }\end{array}$ & $\begin{array}{c}\text { LNG after } \\
\text { pressurization }\end{array}$ & $\begin{array}{c}\text { After } \\
\text { gasification }\end{array}$ \\
\hline Pressure (bar) & 1,01325 & 90 & 90 \\
Temperature $\left({ }^{\circ} \mathrm{C}\right)$ & -162 & -160 & 5 \\
Flow rate $(\mathrm{kg} / \mathrm{s})$ & & 44,44 & \\
Composition & & Methane & \\
\hline
\end{tabular}

We perform in this section the energy and exergy analysis of LNG during gasification. To do this, the general equations of energy and exergy balances are presented.

For an open thermodynamic system in steady state, where the variations of kinetic and potential energies are negligible [7], the energy balance equation (1st law of thermodynamics) can be written as follows:

$\sum \dot{\mathrm{Q}}_{\mathrm{i}}+\dot{\mathrm{W}}+\sum \dot{\mathrm{m}}_{\text {in }} \mathrm{h}_{\text {in }}-\sum \dot{\mathrm{m}}_{\text {out }} \mathrm{h}_{\text {out }}=0$
Meratizaman et al [8] enumerate the different types of exergy in a system: chemical exergy, physical exergy, potential exergy, kinetic exergy, work exergy and heat transfer exergy. For an open system where no chemical reaction occurs, potential and kinetic exergy are often neglected. The general exergy balance is expressed as:

$\sum \tau_{\mathrm{i}} \dot{\mathrm{Q}}_{\mathrm{i}}+\dot{\mathrm{W}}+\sum \dot{\mathrm{m}}_{\mathrm{in}} \psi_{\text {in }}-\sum \dot{\mathrm{m}}_{\text {out }} \psi_{\text {out }}-\dot{\mathrm{Ex}}_{\mathrm{d}}=0$

where $\tau_{\mathrm{i}}$ is the Carnot factor

$\tau_{\mathrm{i}}=\left(1-\frac{\mathrm{T}_{0}}{\mathrm{~T}_{\mathrm{i}}}\right)$

$\dot{W}$ is the rate of work exergy, the term $\sum \tau_{i} \dot{Q}_{i}$ is the heat transfer exergy, $\dot{E} x_{\text {dest }}$ is the rate of exergy destruction,$\psi$ is the physical specific exergy flow

$\psi=\left(\mathrm{h}-\mathrm{h}_{0}\right)-\mathrm{T}_{0}\left(\mathrm{~s}-\mathrm{s}_{0}\right)$

$\mathrm{h}_{0}$ and $\mathrm{s}_{0}$ are specific enthalpy and entropy at the reference state of $\mathrm{T}_{0}$ and $\mathrm{P}_{0}$.

The application of the energy balance on the LNG vaporization process allows calculating the heat flow required for the vaporization of $\mathrm{LNG}$.

$\dot{\mathrm{Q}}_{\mathrm{LNG}}=\dot{\mathrm{m}}_{\mathrm{LNG}}\left(\mathrm{h}_{\mathrm{LNG}, \text { out }}-\mathrm{h}_{\mathrm{LNG}, \text { in }}\right)$

Change in physical exergy of LNG during gasification is given by:

$$
\begin{aligned}
\dot{\mathrm{E}} \mathrm{x}_{\mathrm{LNG}}= & \dot{\mathrm{m}}_{\mathrm{LNG}} \Delta \psi \\
=\dot{\mathrm{m}}_{\mathrm{LNG}} & {\left[\left(\mathrm{h}_{\mathrm{LNG}, \text { out }}-\mathrm{T}_{0} \mathrm{~s}_{\mathrm{LNG}, \text { out }}\right)-\left(\mathrm{h}_{\mathrm{LNG}, \text { in }}-\mathrm{T}_{0} \mathrm{~s}_{\mathrm{LNG}, \text { in }}\right)\right] } \\
= & \tau_{\mathrm{LNG}} \dot{\mathrm{Q}}_{\mathrm{LNG}}
\end{aligned}
$$

The Carnot factor $\tau_{\mathrm{LNG}}$, corresponds to the average entropic temperature of the LNG defined by:

$T_{\mathrm{LNG}}=\frac{\mathrm{h}_{\mathrm{LNG}, \text { in }}-\mathrm{h}_{\mathrm{LNG}, \text { out }}}{\mathrm{s}_{\mathrm{LNG}, \text { in }}-\mathrm{s}_{\mathrm{LNG}, \text { out }}}$

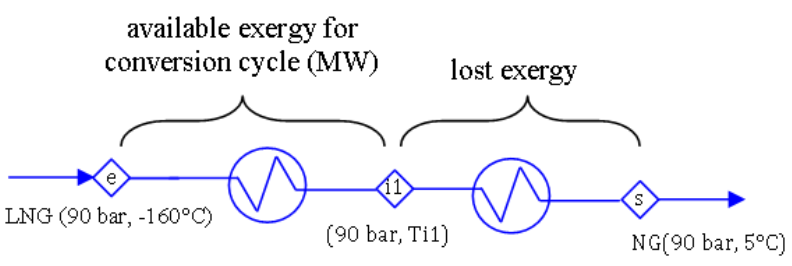

Figure 1.cold exergy use.

Overall exergy resource is calculated by Eq. (6) between $-160^{\circ} \mathrm{C}$ and $5^{\circ} \mathrm{C}$ (Figure 1), amount of this exergy is assumed to be valorised in an engine cycle working between ambient air as heat source and LNG as cold sink. The remaining part of exergy is lost by heating the LNG directly with ambient air. The valorised part starts at the LNG supply temperature $\left(-160^{\circ} \mathrm{C}\right)$ and ends at the temperature Til (see Figure 1). From Ti1 to $5^{\circ} \mathrm{C}$, the $\mathrm{LNG}$ exergy is lost.

For a gasification pressure of 90 bar, a heat flux of 33 $\mathrm{MW}$ is required to vaporize and heat a typical flow rate of an LNG gasification module of $160 \mathrm{t} / \mathrm{h}$ from $-160{ }^{\circ} \mathrm{C}$ to 5 ${ }^{\circ} \mathrm{C}$ (see Table 1), the cold sink (liquid methane) presents an 
exergy change of 17.47 MW if all the exergy content from $160{ }^{\circ} \mathrm{C}$ to $5^{\circ} \mathrm{C}$ is valorised.

By varying Ti1, both the heat flow transferred to LNG and cold exergy flow available for valorisation are plotted, respectively, in Figure 2 and 3. Figure 2 shows that the gasification takes place with a temperature glide because it occurs at a pressure above the critical pressure. A slope change occurs after $-40{ }^{\circ} \mathrm{C}$. For a temperature higher than $40{ }^{\circ} \mathrm{C}$, the additional available exergy becomes small. Indeed, 16.4 MW of exergy is available between -160 and $40{ }^{\circ} \mathrm{C}$ (Figure 3), while between -40 and $5{ }^{\circ} \mathrm{C}$ the available exergy of LNG is $1.05 \mathrm{MW}$. In conclusion, the LNG exergy recovery with engine cycles seems interesting between -160 ${ }^{\circ} \mathrm{C}$ and $-40{ }^{\circ} \mathrm{C}$.

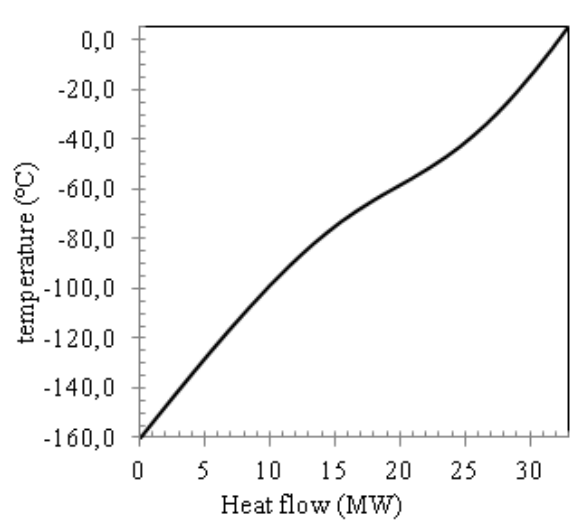

Figure 2. Evolution of outlet temperature of $L N G$ versus heating power $(P=90$ bar $),($ REFPROP $)$.

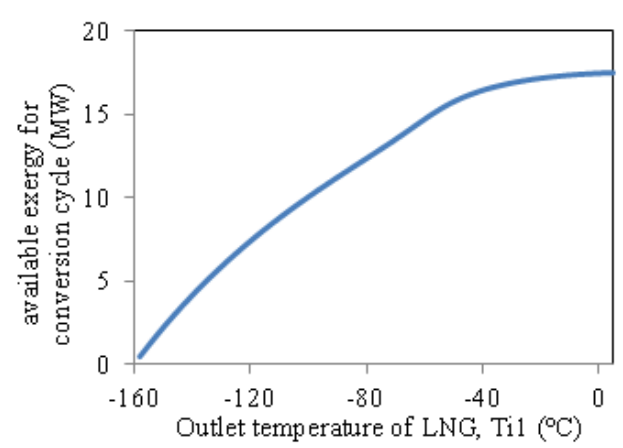

Figure 3. Evolution of available exergy of $L N G(T 0=15$ $\left.{ }^{\circ} \mathrm{C}\right)$ according to the outlet temperature of $L N G(P=90$ bar).

3. Thermodynamic Architecture of Engine Cycles Recovering LNG Exergy Designed by Energy and Exergy Analysis

During the gasification / heating of LNG, total available exergy ( $\mathrm{P}=90 \mathrm{bar}$ ) is $17.47 \mathrm{MW}$ for $160 \mathrm{t} / \mathrm{h}$ of LNG. However, most of the available exergy is in the temperature range where the $\mathrm{LNG}$ passes from $-160{ }^{\circ} \mathrm{C}$ to $-40{ }^{\circ} \mathrm{C}$, this available exergy is $16.42 \mathrm{MW}$.

This section aims to design the thermodynamic architecture of real engines. The methodology we apply is a systemic approach combining the pinch methodology and exergy analysis. We evaluate the destroyed exergy in each component of proposed set of thermodynamic engine cycle as well as the relationship between the working fluid and the destruction of exergy. Unlike a conventional engine cycle, the heat source is the ambient air supposed here to be at the reference temperature $\mathrm{T} 0=288.15 \mathrm{~K}\left(15^{\circ} \mathrm{C}\right)$. A recovery by one or two cascading engines is proposed (Figure 4). Heat is transferred from the heat source, the environment (via a two phase secondary fluid, e.g. propane) to the engines by condensation in the evaporators (in the case of Rankine systems) or the heater (in the case of Brayton system) of engines. The secondary fluid is evaporated in air heat exchangers. This evaporationcondensation resulting in a transfer of heat from the ambient air to the engines at nearly constant temperature which helps to limit frost formation. Exergy is traded in the opposite direction of heat flow.

$\dot{E} x_{i}=\tau_{i} \dot{Q}_{i}$

Carnot factors, $\tau_{\mathrm{i}}$, are negative because $\mathrm{T} 0>\mathrm{T}_{\mathrm{i}}$, involving a sign inversion of the exergy flow compared to heat flow. The sign convention adopted states that the energy received by the system is positive and the energy transferred by the system is negative. The end of the gasification / heating of LNG (after leaving the engines) is done without exergy recovery which is simply lost in a heat exchanger between the secondary fluid and the gas. The maximization of recovery requires the minimization of the total destroyed/lost exergy. Exergy destruction is the sum total of exergy destroyed in the engine cycles and exergy lost by the LNG in the heat transfer fluid loop.

In a conventional engine cycle, the atmosphere is often the cold sink where heat is rejected. The corresponding exergy efficiency allows evaluating the converted amount of the heat supplied by the heat source. In this study, the availability of a cold sink at very low temperatures allows the use air or the external environment as a heat source. It is necessary to highlight this characteristic where a cold exergy is consumed to produce mechanical work. Figure 4 shows that the incoming heat flow (orange arrows) comes from the heat source, while the incoming exergy flows (blue arrows) from the cold sink.

The energy efficiency of the first and second cycle engine are given by Eq. (9)

$\left\{\begin{array}{l}\eta_{\text {en,cyc1 }}=-\dot{W}_{\text {сус1 }} / \dot{Q}_{i n, \mathrm{cyc} 1} \\ \eta_{\text {en,cyc2 }}=-\dot{W}_{\text {сус2 }} / \dot{Q}_{i n, \mathrm{cyc} 2}\end{array}\right.$

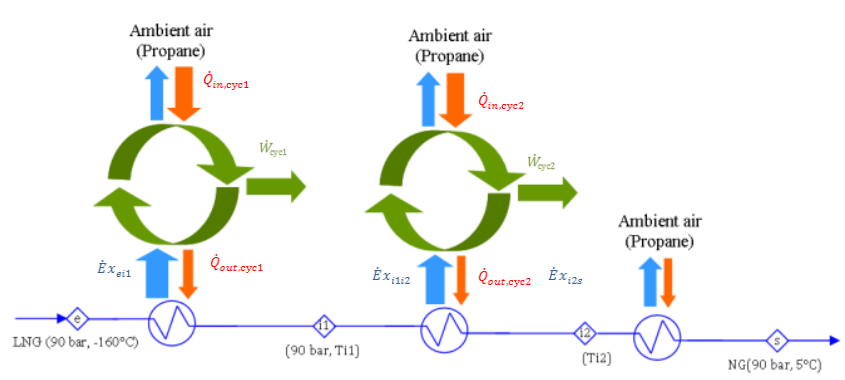

Figure 4. Heat and exergy flow.

The exergy efficiency is the ratio between the useful exergy (useful work) and input exergy of LNG. In our case, the exergy efficiency of engine cycles is defined according 
to the cold sink that provides exergy to the engine cycles (Figure 4).

$\left\{\begin{array}{l}\eta_{e x, \mathrm{cyc} 1}=-\dot{W}_{\mathrm{cyc} 1} / \dot{E} x_{e i 1} \\ \eta_{e x, \mathrm{cyc} 2}=-\dot{W}_{\mathrm{cyc} 2} / \dot{E} x_{i 1 i 2}\end{array}\right.$

The overall exergy efficiency is defined by the ratio between the total recovered mechanical work and the total available exergy of LNG (17.47 MW)

$\eta_{e x, g}=-\left(\dot{W}_{\text {сус } 1}+\dot{W}_{\text {сус } 2}\right) / \dot{E} x_{e, s}$

\subsection{Engine Cycles Options and Constraints}

In order to produce mechanical work using LNG as a cold sink, several thermodynamic cycles are investigated. The production of mechanical work using a heat source and a cold sink occurs with four thermodynamic transformations which form a thermodynamic cycle. The working fluid is first compressed in liquid state (Rankine) or vapour state (Brayton), then heated (Brayton) or vaporised (Rankine) and then expanded in a turbine to produce mechanical work. To return to the initial state, the fluid is cooled (Brayton) or condensed (Rankine) by a cold sink (LNG). The difference between the work of compression and the work generated by the turbine is the net work of the engine cycle.

We focus on three types of real engine cycles, the Brayton cycle (Figure 5a), the Rankine cycle (Figure 5c and d) and the transcritical Rankine cycle (Figure 5b).

For a fluid whose critical point is very low, a Brayton cycle is built (Figure 5a). The working fluid is compressed in the vapor state, the energy consumption and the irreversibilities of this operation are larger than the case of Rankine cycle where the passage from the low pressure to high pressure takes place in the liquid state. The advantage of the Brayton cycle is the cooling section where the working fluid has a temperature change that matches the one of LNG. Indeed, the exergy destruction in the vaporizer of $\mathrm{LNG}$ is minimized by reducing the temperature difference between the working fluid and LNG. However, the heat transfer between propane (heat source) and the working fluid will be subject to significant exergy destruction due to the high temperature difference between the working fluid and the heat source (nearly constant temperature).

If the critical point is quite high $\left(\mathrm{Tc}>40{ }^{\circ} \mathrm{C}\right.$ ), it is possible to build a Rankine cycle (Figure $5 \mathrm{c}$ and d). Unlike a Brayton cycle, the process that causes the highest destruction of exergy is the gasifier of LNG. However, the heat transfer between the heat source and the working fluid occurs with low temperature range where less exergy is destroyed. For a non-azeotropic mixture, the phase change takes place with temperature glide (Figure 5d), which makes it possible to get closer to the temperature profile of the LNG and to have a higher exergy yield from the gasifier.

In a transcritical cycle, the high pressure is higher than the critical pressure (Figure 5b). The working fluid is changing phase at low pressure. Heat transfer between the working fluid and the external fluids occur with important exergy destruction as a result of large temperature difference between the working fluid and the external fluids (on both sides). This results in making the transcritical Rankine cycle non suitable for this valorization.
In the analysis of real cycles, a heat exchangers pinch of $5 \mathrm{~K}$ is assumed in this study. The nonlinearity of the evolution of the LNG in the heat exchanger leads to a pinch which is not always located at the extremities of the gasifier, which leads to additional exergy destruction. In addition to the irreversibilities in heat exchangers, the compression or expansion of a fluid is prone to destruction of exergy. The isentropic efficiency of compressors or pumps and turbines is assumed to be $80 \%$.

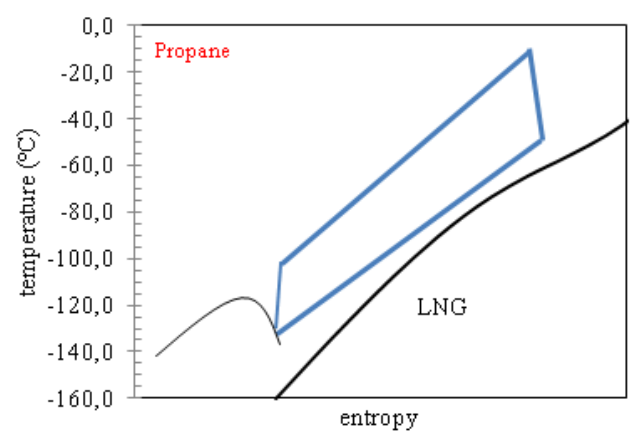

Figure 5 a) Recovery of exergy of LNG using a Brayton cycle.

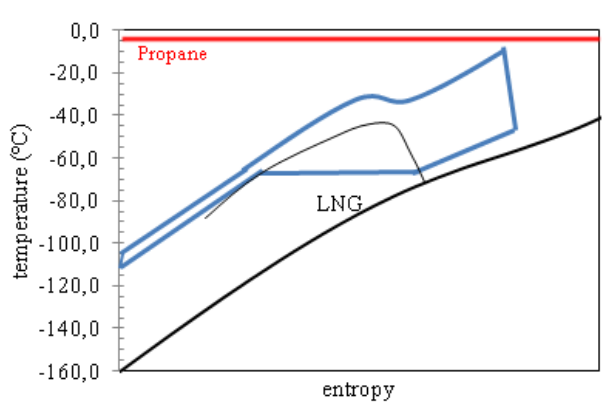

Figure 5 b) Recovery of exergy of $L N G$ using a transcritical cycle.

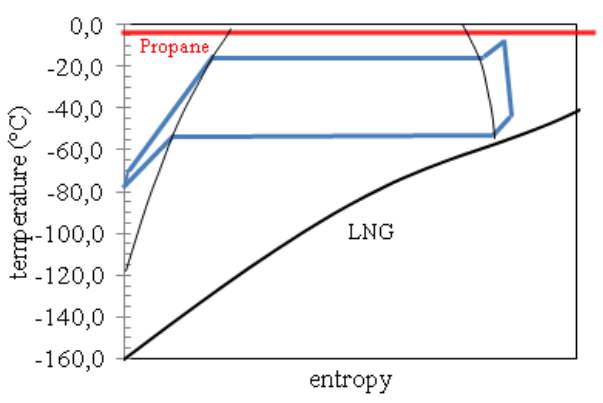

Figure 5 c) Recovery of exergy of $L N G$ using a Rankine cycle (pure fluid or azeotropic mixture).

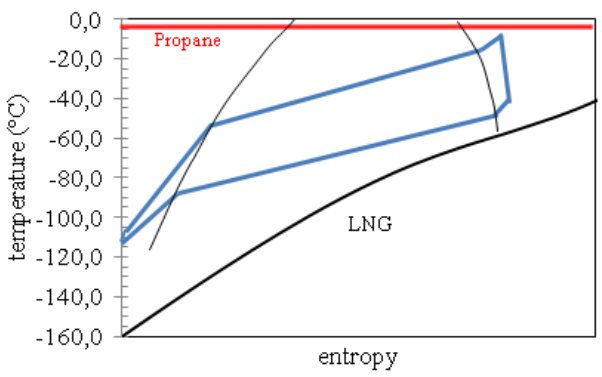

Figure 5 d) Recovery of exergy of $L N G$ using a Rankine cycle (non-azeotropic mixture).

Some fluids may present a triple point temperature higher than $-160{ }^{\circ} \mathrm{C}$, which is a constraint on the thermodynamic cycle, mainly on low pressure side. This 
imposes a greater temperature difference between the LNG and working fluid keeping the working fluid at a temperature higher than its triple point.

The use of a regenerator (internal heat exchanger) can, in some cases, significantly improve cycle efficiency (Figure 6). The ratio between the useful power produced by the cycle and the heat flow supplied by the heat source increases because the heat source supplies less heat flow to the cycle, while producing the same mechanical work. The regenerator allows using less cold from the LNG and thus, it enables a second engine cycle to recover the residual exergy. The regenerator is an additional source of irreversibilities that must be taken into consideration.

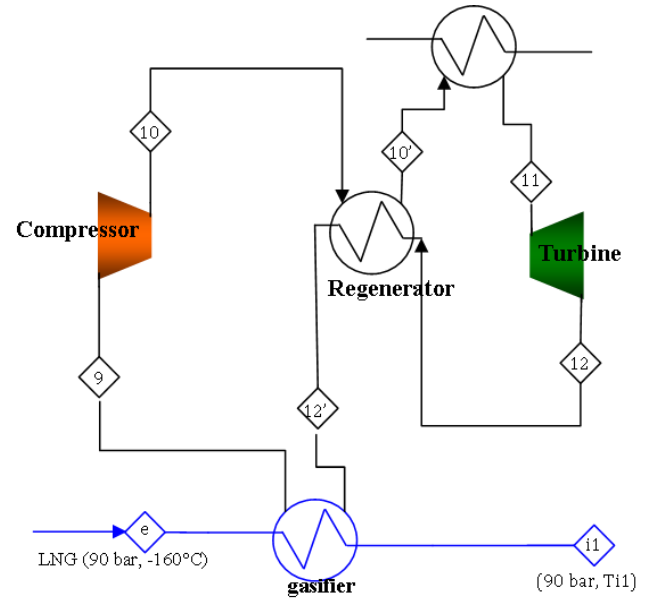

Figure 6. a) Schematic of a Brayton cycle with regenerator.

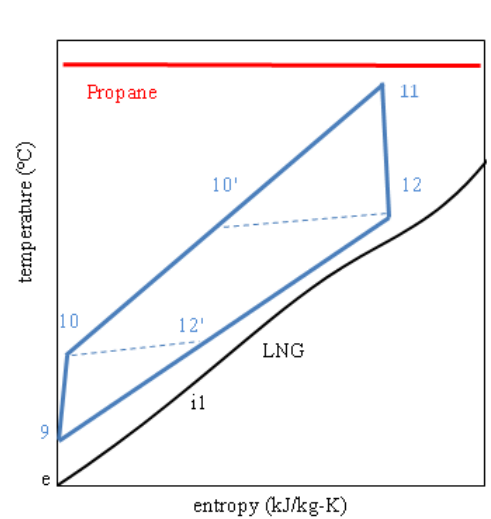

Figure 6. b) T-s Diagram.

In the case of a Brayton cycle without regenerator, the LNG outlet temperature is a function of the pressure ratio $\frac{\mathrm{HP}}{\mathrm{LP}}$. Indeed for a polytropic expansion, the relationship between the temperature of the beginning of expansion $\mathrm{T}_{11}$ and temperature $\mathrm{T}_{12}$ is only a function of the pressure ratio.

$\frac{\mathrm{T}_{11}}{\mathrm{~T}_{12}}=\left(\frac{\mathrm{HP}}{\mathrm{LP}}\right)^{\frac{\mathrm{k}-1}{\mathrm{k}}}$

Temperature of the beginning of expansion $\mathrm{T}_{11}$ is obtained from the heat source temperature and the heat exchanger pinch assumption, it is therefore considered constant. The turbine outlet temperature $\mathrm{T}_{12}$ imposing the outlet temperature of the LNG is only function of the pressure ratio $\frac{\mathrm{HP}}{\mathrm{LP}}$. The outlet temperature of the LNG determines the possibility of designing engines cascade. As cycle efficiency is deteriorated when increasing temperature of the cold sink, a cascade of maximum two cycles seems to be a reasonable option, the addition of a third cycle stage presents a low ratio cost/benefit.

The use of a two engine cycles cascade improves performance by reducing the overall exergy destruction associated with very important temperature glide during heating of methane which induces large temperature differences with the working fluid. The cascade reduces the average temperature difference at the gasifier and the heat exchanger "working fluid / heat source."

\subsection{Working fluids}

Table 2. Investigated working pure fluids.

\begin{tabular}{|c|c|c|c|c|c|}
\hline Fluid & Ccycle & $\begin{array}{l}P c \\
\text { (bar) }\end{array}$ & $\begin{array}{l}T c \\
\left({ }^{\circ} \mathbf{C}\right)\end{array}$ & $\begin{array}{l}\text { Triple } \\
\text { point } \\
\left({ }^{\circ} \mathrm{C}\right)\end{array}$ & $\begin{array}{l}T b \\
\left({ }^{\circ} \mathrm{C}\right)\end{array}$ \\
\hline Nitrogen & Brayton & 33.958 & -146.9 & -210 & -195.91 \\
\hline Oxygen & Brayton & 50.43 & -118.5 & -218.79 & -183.09 \\
\hline Methane & Brayton & 45.992 & -82.5 & -182.46 & -161.64 \\
\hline Ethylene & Rankine & 50.418 & 9.2 & -169.16 & -103.99 \\
\hline Ethane & Rankine & 48.719 & 32.1 & -182.8 & -88.842 \\
\hline
\end{tabular}

Table 3. Investigated mixture with Rankine cycle.

\begin{tabular}{|c|c|c|c|c|}
\hline$T b$ (1 bar) & & & & \\
\hline $\begin{array}{l}\text { Mixtures (mole } \\
\text { fraction) }\end{array}$ & $\begin{array}{l}\text { Pc } \\
\text { (bar) }\end{array}$ & $\begin{array}{l}\text { Tc } \\
\left({ }^{\circ} \mathrm{C}\right)\end{array}$ & $\begin{array}{l}\text { Liquid } \\
\text { Temp. } \\
\left({ }^{\circ} \mathrm{C}\right)\end{array}$ & $\begin{array}{l}\text { Vapor } \\
\text { temp. } \\
\left({ }^{\circ} \mathrm{C}\right)\end{array}$ \\
\hline $\begin{array}{l}\text { Methane, } 0.76 \text {; ethane, } \\
0.24\end{array}$ & 68.962 & -40.06 & -158.86 & -111.43 \\
\hline $\begin{array}{l}\text { Methane, } 0.66 \text {, ethane } \\
0.34\end{array}$ & 71.062 & -26.30 & -157.55 & -106.57 \\
\hline $\begin{array}{l}\text { methane, } 0.64 \text {; ethane } \\
0.34 \text {, } \\
\text { propane, } 0.02\end{array}$ & 71.201 & -22.09 & -157.31 & -96.249 \\
\hline $\begin{array}{l}\text { methane, } 0.50 \text {, ethane, } \\
0.50\end{array}$ & 69.022 & -7.819 & -154.61 & -100.74 \\
\hline $\begin{array}{l}\text { methane, } 0.54 \text {; ethane } \\
0.34 \text {, } \\
\text { propane, } 0.12\end{array}$ & 72.117 & -0.586 & -155.89 & -78.293 \\
\hline $\begin{array}{l}\text { methane, } 0.44 \text {; ethane } \\
0.34 \text {, } \\
\text { propane, } 0.22\end{array}$ & 70.702 & 19.264 & -153.92 & -69.674 \\
\hline $\begin{array}{l}\text { methane, } 0.10 \text {; ethane, } \\
0.90\end{array}$ & 53.4 & 25.723 & -126.12 & -90.778 \\
\hline $\begin{array}{l}\text { methane, } 0.25 \text {, ethane } \\
0.50 \text {, } \\
\text { propane, } 0.25\end{array}$ & 62.767 & 37.191 & -145.85 & -66.659 \\
\hline $\begin{array}{l}\text { methane, } 0.33 \text {, ethane } \\
0.33 \text {, } \\
\text { propane } 0.34\end{array}$ & 66.564 & 38.028 & -150.74 & -62.979 \\
\hline
\end{tabular}

The critical point (critical temperature and critical pressure) and the normal boiling point allow selecting candidate fluids (Table 2 and 3). These properties give an indication on the type of thermodynamic cycle and level of pressure. Knowing that the high pressure leads to mechanical stress on equipment and has an impact on cost, it is limited in this study to 130 bar.

Five pure fluids (Nitrogen, Oxygen, Methane, Ethane and Ethylene) and hydrocarbon mixtures are proposed. The mixtures are composed of methane, ethane and propane. They are chosen in order to obtain a pseudo critical temperature of mixture between -40 and $40{ }^{\circ} \mathrm{C}$.

\subsection{Energy and Exergy Analysis}

The analysis is performed by evaluating the exergy destruction in the different components of a cycle (turbine, heat exchangers, pumps ...), in addition to the exergy lost at the end of heating (at the heat transfer fluid loop). 
Exergy losses depend on the outlet temperature of LNG from engine cycles, all the available exergy of LNG between Ti2 and Ts (see Figure 4) is lost:

$\dot{\mathrm{E}} \mathrm{x}_{\text {lost }}=\left|\dot{\mathrm{E}} \mathrm{x}_{\mathrm{i} 2 \mathrm{~s}}\right|$

The exergy balance applied to the first and the second engine cycles allows evaluating the total exergy destruction of both engines

$$
\begin{aligned}
& \dot{\mathrm{E}} \mathrm{x}_{\mathrm{d}, \mathrm{cyc}}=\dot{\mathrm{E}} \mathrm{x}_{\mathrm{d}, \mathrm{cyc} 1}+\dot{\mathrm{E}} \mathrm{x}_{\mathrm{d}, \mathrm{cyc} 2} \\
& \text { with } \\
& \left\{\begin{array}{l}
\dot{\mathrm{E}} \mathrm{x}_{\mathrm{d}, \mathrm{cyc} 1}=\dot{\mathrm{E}} \mathrm{x}_{\mathrm{ei} 1}+\dot{\mathrm{W}}_{\mathrm{cyc} 1} \\
\dot{\mathrm{E}} \mathrm{x}_{\mathrm{d}, \mathrm{cyc} 2}=\dot{\mathrm{E}} \mathrm{x}_{\mathrm{i} 1 \mathrm{i} 2}+\dot{\mathrm{W}}_{\mathrm{cyc} 2}
\end{array}\right.
\end{aligned}
$$

The exergy efficiency of the first cycle engine is written as a function of the exergy destruction $\dot{E x}_{\mathrm{d}, \mathrm{cyc} 1}$ [9] of all elements of the cycle

$\eta_{\text {ex,cyc1 }}=1-\frac{\dot{E} x_{\mathrm{d}, \mathrm{cyc} 1}}{\dot{\text { Ex }} \mathrm{x}_{\mathrm{e} 1}}$

$\dot{\mathrm{E}} \mathrm{x}_{\mathrm{ei} 1}$ is exergy available between $-160{ }^{\circ} \mathrm{C}$ and the discharge temperature of the LNG Ti1. Similarly, the exergy efficiency of the second engine recovering the cold of LNG $\mathrm{T}_{\mathrm{i} 1}$ to $\mathrm{T}_{\mathrm{i} 2}$ is calculated by Eq. 17

$\eta_{\mathrm{ex}, \mathrm{cyc} 2}=1-\frac{\dot{\mathrm{E}} \mathrm{x}_{\mathrm{d}, \mathrm{cyc} 2}}{\dot{\mathrm{E}} \mathrm{x}_{\mathrm{i} 1 \mathrm{i} 2}}$

The cycle construction and working fluid selection aim at minimizing the overall exergy destruction given by Eq. (18).

$\dot{\mathrm{E}} \mathrm{x}_{\mathrm{d}, \mathrm{g}}=\dot{\mathrm{E}} \mathrm{x}_{\text {lost }}+\dot{\mathrm{E}} \mathrm{x}_{\mathrm{d}, \mathrm{cyc}}$

The application of exergy balance on each cycle components (turbines, heat exchangers, compressors or pumps...) allows evaluating the contribution of each component to the total exergy destruction of a cycle.

\section{Results and Discussion}

First we focus on a recovery with one engine cycle. After presenting the best solution with one engine cycle, we study the possibility of adding a second cycle in order to improve the overall exergy efficiency. In order to optimize the cycle for each fluid, the parameters of the engine cycle are calculated by varying pressure levels which are characterized by two variables: the low pressure (LP) and the pressure ratio (HP/LP). The gasifiers and regenerators pinch is kept equal to $5 \mathrm{~K}$. Thermodynamic cycles are modelled using Visual Basic associated with REFPROP [9] for the calculation of thermodynamic properties. The flow rate of the working fluid is derived from the equation of energy balance of the gasifier. The cycle which provides the highest overall exergy efficiency $(12.5 \%)$ is the ethane Rankine cycle; $2165 \mathrm{~kW}$ useful mechanical power is produced. The usage of non-azeotropic mixtures in order to improve the exergy efficiency of the gasifier, taking advantage of temperature glide of this type of mixture has not improved the overall exergy efficiency. Nitrogen Brayton cycle with regenerator has the least internal irreversibilities; it has an exergy efficiency of $20.5 \%$. This performance was calculated in the case of optimal overall exergy efficiency estimated at $11.2 \%$. Thus, nitrogen Brayton with regenerator is the cycle that has the highest efficiency $(17.8 \%)$. In the case of a recovery with two engine cycles, it would be interesting to use cycles that generate fewer irreversibilities in the search for the best cycles combination.

Several combinations of engine cycles were investigated. Exergy analysis of LNG cold energy recovery with a single engine cycle allows to choose the right combinations for the cascade system. Cycles with high exergy efficiency are selected. The cascade giving the maximum power is composed by respectively a nitrogen Brayton cycle with regenerator and ethane Rankine cycle, the power that can be generated is $3105 \mathrm{~kW}$ according to a LNG flow rate of $44.44 \mathrm{~kg} / \mathrm{s}$.

Nitrogen Brayton cycle with regenerator is chosen as the first cycle, because this thermodynamic cycle presents the best exergy efficiency, which means that the cycle is the one which has the least internal exergy destruction (compressor, turbine, heat exchangers). For the second cycle, our first choice is the ethane Rankine cycle which has the best overall exergy efficiency in the case of single cycle use. The goal is to complete the recovery with an optimal overall exergy efficiency without worrying about internal exergy destruction for the second cycle. The total exergy destroyed in the various elements of the two engine cycles and the lost exergy at the end of LNG heating is minimized. Using Excel Solver, the optimal overall exergy efficiency is found to be $17.8 \%$. $65.3 \%$ of LNG physical exergy is destroyed because of both engine cycles irreversibilities. The LNG exits from the first cycle at $111.5^{\circ} \mathrm{C}$ and from the second engine at $-61.4{ }^{\circ} \mathrm{C}$. Starting from this temperature, the remaining exergy represents only $16.9 \%$ of total LNG exergy. This remaining exergy is lost at the heat transfer fluid.

\section{Conclusions}

The energy and exergy analysis has identified engine cycles architectures using air as a heat source (recovered by an intermediate fluid which is propane) and LNG as cold sink. Exergy analysis has identified and quantified the main sources of irreversibility. In order to define the best recovery thermodynamic architecture with a single engine cycle, several working fluids were investigated with different types of cycles (Rankine and Brayton). The cycle having the best overall exergy efficiency is the ethane Rankine cycle, $12.5 \%$ of physical exergy of LNG is recovered in the form of mechanical energy. This cycle can produce $2165 \mathrm{~kW}$ of electricity. We also identified an interesting cycle which is the nitrogen Brayton cycle with regenerator (internal heat exchanger) which has the best energy and exergy cycle efficiencies. This allows investigating for a second downstream cycle. We have seen that in a recovery solution with a single engine cycle, the ethane Rankine cycle has significant irreversibilities where $39.0 \%$ of the total exergy of LNG is destroyed. This is due to the large temperature difference between the working fluid and LNG. Improving the overall exergy efficiency involves the reduction of exergy destruction in the gasifier and in the " working fluid/propane (atmosphere)" heat exchanger. To do this, a solution of gasification by two cycles in series has been studied. The use of a nitrogen Brayton cycle with regenerator associated to an ethane Rankine cycle produces $3,105 \mathrm{~kW}$ of electricity. Thanks to this combination the overall exergy efficiency was improved from $12.5 \%$ to $17.8 \%$. 


\begin{tabular}{ll}
\multicolumn{2}{l}{ Nomenclature } \\
$\dot{\text { Ex }}$ & Exergy flow, W \\
$\dot{\mathrm{m}}$ & Masse flow rate, $\mathrm{kg} \mathrm{s}-1$ \\
$\dot{\mathrm{Q}}$ & Heat flow, W \\
$\dot{\mathrm{W}}$ & Rate of work (or power), W \\
$\mathrm{h}$ & Specific enthalpy, J kg-1 \\
$\mathrm{HP}$ & high pressure, Pa \\
$\mathrm{LP}$ & Low pressure, Pa \\
$\mathrm{s}$ & Specific entropy, J kg-1K-1 \\
$\mathrm{Tb}$ & Normal boiling temperature, ${ }^{\circ} \mathrm{C}$ \\
Greek letters \\
$\eta_{\text {ex,g }}$ & Overall exergy efficiency \\
$\eta_{\mathrm{en}}$ & Energy efficiency \\
$\eta_{\mathrm{ex}}$ & Exergy efficiency \\
$\Psi$ & Physical specific exergy flow, J kg-1] \\
$\mathrm{T}$ & Carnot factor \\
Indices & \\
$\mathrm{a}$ & Air \\
$\mathrm{C}$ & Critical \\
comp & Compressor \\
cyc1, cyc2 & Engine cycle 1 et 2 \\
$\mathrm{D}$ & Destruction (exergy) \\
$\mathrm{e}, \mathrm{i} 1, \mathrm{i} 2, \mathrm{~s}$ & Thermodynamic states of LNG \\
$\mathrm{G}$ & overall \\
$\mathrm{I}$ & Summation index \\
in & Inlet \\
out & Outlet \\
reg & Regenerator \\
turb & Turbine \\
wf & Working fluid \\
&
\end{tabular}

\section{References}

[1] F. Bai and Z. Zhang, "Integration of low-level waste heat recovery and liquefied nature gas cold energy utilization," Chinese J. Chem. Eng., 16, 95-99, 2008.

[2] C. Dispenza, G. Dispenza, V. La Rocca, and G. Panno, "Exergy recovery during LNG regasification: Electric energy production - Part one," Appl. Therm. Eng., 29, 380-387, 2009.

[3] G. Angelino and C. M. Invernizzi, "The role of real gas Brayton cycles for the use of liquid natural gas physical exergy," Appl. Therm. Eng., 31, 827-833, 2011.

[4]T. Lu and K. S. Wang, "Analysis and optimization of a cascading power cycle with liquefied natural gas (LNG) cold energy recovery," Appl. Therm. Eng., 29, 14781484, 2009.

[5] W. Qiang, L. Yanzhong, and W. Jiang, "Analysis of power cycle based on cold energy of liquefied natural gas and low-grade heat source," Appl. Therm. Eng., 24, 539-548, 2004.

[6] X. Shi and D. Che, "Thermodynamic analysis of an LNG fuelled combined cycle power plant with waste heat recovery and utilization system," Int. J. energy Res., 31, 975-998, 2007.

[7] F. Meunier, (2004) Aide-mémoire: Thermodynamique de l'ingénieur, Énergétique, Environnement, Dunod.

[8] M. Meratizaman, M. Amidpour, S. A. Jazayeri, and K. Naghizadeh, "Energy and exergy analyses of urban waste incineration cycle coupled with a cycle of changing LNG to pipeline gas," J. Nat. Gas Sci. Eng., 2, 217-221, 2010 .

[9] F. Ayachi, E. B. Ksayer, and P. Neveu, "Exergy Assessment of Recovery Solutions from Dry and Moist Gas Available at Medium Temperature," Energies, 5, 718-730, 2012. 